\title{
Genomic methods in profiling DNA accessibility and factor localization
}

\author{
David C. Klein (D) - Sarah J. Hainer (i)
}

Received: 17 September 2019 / Revised: 10 October 2019 / Accepted: 15 October 2019/Published online: 27 November 2019

(C) The Author(s) 2019

\begin{abstract}
Recent advancements in next-generation sequencing technologies and accompanying reductions in cost have led to an explosion of techniques to examine DNA accessibility and protein localization on chromatin genome-wide. Generally, accessible regions of chromatin are permissive for factor binding and are therefore hotspots for regulation of gene expression; conversely, genomic regions that are highly occupied by histone proteins are not permissive for factor binding and are less likely to be active regulatory regions. Identifying regions of differential accessibility can be useful to uncover putative gene regulatory regions, such as enhancers, promoters, and insulators. In addition, DNA-binding proteins, such as transcription factors that preferentially bind certain DNA sequences and histone proteins that form the core of the nucleosome, play essential roles in all DNA-templated processes. Determining the genomic localization of chromatin-bound proteins is therefore essential in determining functional roles, sequence motifs important for factor binding, and regulatory networks controlling gene expression. In this review, we discuss techniques for determining DNA accessibility and nucleosome positioning
\end{abstract}

Responsible Editor: Beth Sullivan.

D. C. Klein · S. J. Hainer $(\bowtie)$

Department of Biological Sciences, University of Pittsburgh,

Pittsburgh, PA 15260, USA

e-mail: sarah.hainer@pitt.edu
(DNase-seq, FAIRE-seq, MNase-seq, and ATACseq) and techniques for detecting and functionally characterizing chromatin-bound proteins (ChIP-seq, DamID, and CUT\&RUN). These methods have been optimized to varying degrees of resolution, specificity, and ease of use. Here, we outline some advantages and disadvantages of these techniques, their general protocols, and a brief discussion of their development. Together, these complimentary approaches have provided an unparalleled view of chromatin architecture and functional gene regulation.

Keywords Chromatin · DNase · MNase · ATAC · ChIP . CUT\&RUN $\cdot$ nucleosome occupancy $\cdot$ transcription factors $\cdot$ genomics

$\begin{array}{ll}\text { Abbreviations } \\ \begin{array}{l}\text { DHS } \\ \text { DNase-seq }\end{array} & \begin{array}{l}\text { DNase I hypersensitive site } \\ \text { DNase I coupled with deep sequencing } \\ \text { XL-DNase- }\end{array} \\ \text { seq } & \begin{array}{l}\text { Crosslinking DNase I coupled with deep } \\ \text { sequencing }\end{array} \\ \text { scDNase- } & \begin{array}{l}\text { Single-cell DNase I coupled with deep } \\ \text { sequencing }\end{array} \\ \text { seq } & \begin{array}{l}\text { Formaldehyde-assisted isolation of reg- } \\ \text { FAIRE-seq }\end{array} \\ \text { MNase-seq } & \begin{array}{l}\text { Micrococcal nuclease digestion coupled } \\ \text { with deep sequencing }\end{array} \\ \text { MPE-seq } & \begin{array}{l}\text { Methidiumpropyl-EDTA cleavage } \\ \text { coupled with deep sequencing }\end{array} \\ \text { ATAC-seq } & \text { An assay for transposase accessibility }\end{array}$




\begin{tabular}{|c|c|}
\hline ChIP-seq & $\begin{array}{l}\text { Chromatin immunoprecipitation } \\
\text { coupled with deep sequencing }\end{array}$ \\
\hline ChIP-exo & $\begin{array}{l}\text { Chromatin immunoprecipitation } \\
\text { coupled with lambda exonuclease } \\
\text { digestion }\end{array}$ \\
\hline$\mu \mathrm{ChIP}$ & Micro-ChIP \\
\hline STAR-ChIP & $\begin{array}{l}\text { Small-scale TELP-assisted rapid chro- } \\
\text { matin immunoprecipitation }\end{array}$ \\
\hline MINT-ChIP & $\begin{array}{l}\text { Multiplexed, indexed T7 chromatin } \\
\text { immunoprecipitation }\end{array}$ \\
\hline ULI-ChIP & Ultra-low input ChIP \\
\hline DamID & $\begin{array}{l}\text { DNA adenine methyltransferase } \\
\text { identification }\end{array}$ \\
\hline ChIC & Chromatin immunocleavage \\
\hline $\mathrm{ChEC}$ & Chromatin endogenous cleavage \\
\hline CUT\&RUN & $\begin{array}{l}\text { Cleavage under targets and release using } \\
\text { nuclease }\end{array}$ \\
\hline ENCODE & Encyclopedia of DNA elements \\
\hline
\end{tabular}

\section{Background}

All DNA-templated processes that occur in eukaryotic cells do so in the context of chromatin. Chromatin is composed of an array of nucleosomes consisting of 147 base pairs of double-stranded DNA wrapped around an octamer of histone proteins (Kornberg and Lorch 1999). Chromatin is highly regulated to facilitate proper function of DNA-templated processes at the levels of individual nucleosomes, DNA accessibility, and higher-order structures - all of which are regulated by chromatininteracting factors. These chromatin-interacting factors are directed to regions of the genome as both a cause and consequence of local chromatin architecture, creating discrete patterns of factor localization. What emerges is a complex system of reciprocity in which chromatin regulatory factors affect nucleosome architecture, which in turn affects the binding of new regulatory factors. With the dynamic interplay between these processes, diverse methods are necessary to examine nucleosome architecture and regulatory factor binding.

Regulatory elements within a cell are primarily found at open or accessible regions of the genome. Identifying cell-specific regulatory elements is therefore primarily accomplished through accessibility assays. Detecting open chromatin can also identify binding sites for chromatin-interacting proteins. In this review, we will first discuss techniques in the field of chromatin biology for examining chromatin accessibilityincluding digestion with DNase I and deep sequencing (DNase-seq) (Crawford et al. 2006a, b; Sabo et al. 2006; Song and Crawford 2010), formaldehyde-assisted isolation of regulatory elements (FAIRE-seq) (Giresi et al. 2007; Simon et al. 2012), micrococcal nuclease (MNase) digestion followed by deep sequencing (MNase-seq; (Cui and Zhao 2012a; Henikoff et al. 2011; Mieczkowski et al. 2016; Ramani et al. 2019), and an assay for transposase accessibility (ATAC-seq; (Buenrostro et al. 2013, 2015; Chen et al. 2016; Corces et al. 2017); Fig. 1). These techniques provide important context for gene regulation, especially with respect to nucleosome occupancy and positioning.

Importantly, the genomic location of factors or histone proteins cannot be predicted in cell types by DNA sequence or accessibility alone. Individual protein profiling technologies are therefore used to identify the cell-specific characteristics of functional binding. We will discuss techniques for determining factor binding to and localization on chromatin, including chromatin immunoprecipitation (ChIP) (Albert et al. 2007; Furey 2012; Gilmour and Lis 1984; Gilmour et al. 1991; O’Neill 2003; Solomon and Varshavsky 1985), DNA adenine methyltransferase identification (DamID; (Greil et al. 2006; van Steensel and Henikoff 2000), and chromatin immunocleavage-derived techniques (ChIC/CUT\&RUN; (Schmid et al. 2004; Skene and Henikoff 2017) Fig. 2).

Together, the chromatin profiling technologies that assess either accessibility or localization have been refined with increasing precision to improve target signal over background and to reduce necessary cell input in recent years, often reaching their peak with the development of single-cell adaptations of the techniques. Here, we review the technology development, methods, advantages and disadvantages, and optimization for low cell applications.

Section 1: Methods in examining DNA accessibility and chromatin state

Eukaryotic DNA is compacted into the nucleus through interactions between DNA and histone proteins to form chromatin (Lammerding 2011). Generally, the basic repeating unit of chromatin, the nucleosome, poses a significant obstacle to DNA-templated processes, as factors are unable to occupy regions on DNA that are occluded by histone proteins (Beato and Eisfeld 1997; Felsenfeld 1992; Wallrath et al. 1994). Regions of open 


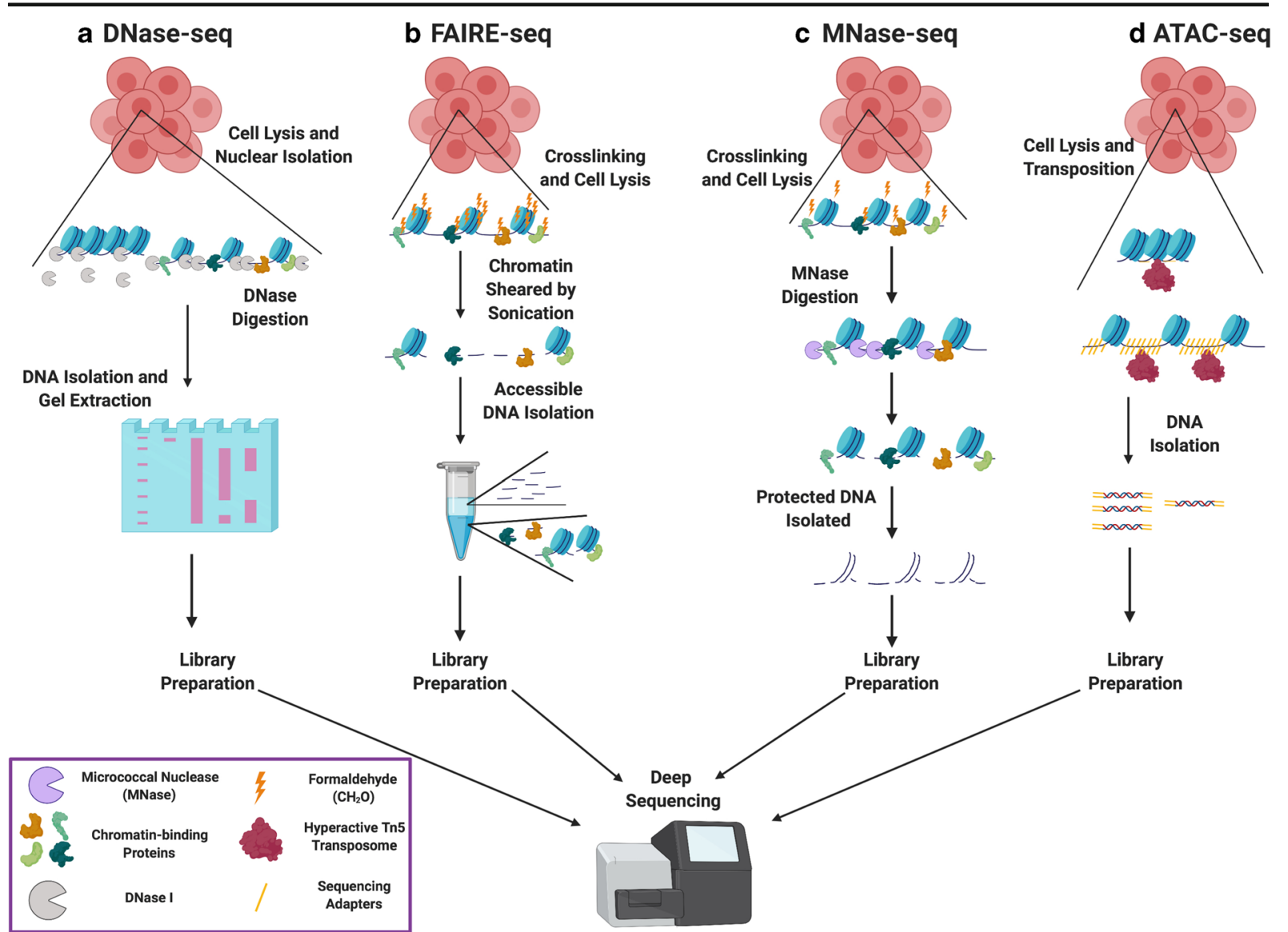

Fig. 1 Methods for mapping genome accessibility. A DNase-seq identifies open regions of chromatin. DNase-seq relies upon preferential digestion of regions of chromatin that are unprotected by bound proteins, leaving behind accessible regions that are known as DNase I hypersensitive sites (DHSs). B FAIRE-seq is dependent on crosslinking of chromatin-interacting proteins to DNA using formaldehyde. Chromatin is then sheared, and regions that are unbound by proteins (e.g., histones) remain in the aqueous layer of a phenol-chloroform extraction, while crosslinked DNA

chromatin, however, are accessible to DNA-binding proteins and are often found at regulatory regions of the genome (Song and Crawford 2010; Thurman et al. 2012). Identifying regions of the genome that are accessible to non-histone proteins therefore provides important information for putative genomic regulatory regions, such as enhancers, promoters, and insulators as well as describing the nucleosome structure of known regulatory regions of the genome (Thurman et al. 2012).

Genomic methods used to examine chromatin accessibility have traditionally been based on preferential enzymatic digestion or modification of accessible DNA to DNA that is protected by bound histone remains in the organic layer. $\mathbf{C}$ MNase-seq profiles nucleosome occupancy and positioning. After formaldehyde crosslinking, added MNase digests DNA that is unprotected by bound proteins, allowing one to infer increased accessibility by decreased presence in sequencing library. D. ATAC-seq relies on the hyperactive Tn5 transposase to insert sequencing adapters at accessible regions of the genome. Following transposition, genomic DNA can be isolated and amplified by PCR, then subjected to deep sequencing. Figure created with Biorender.com

proteins or transcription factors (Fig. 1). Many genomic accessibility techniques (e.g., DNase-seq and MNaseseq) have evolved from long-used nuclease footprinting experiments (Cappabianca et al. 1999; Dingwall et al. 1981; Galas and Schmitz 1978), taking advantage of next-generation sequencing developments to assess genome-wide nucleosome architecture rather than locus-specific footprinting (Crawford et al. 2006b; Schones et al. 2008). The techniques that have emerged are numerous, powerful, and capable of providing highresolution data describing chromatin accessibility. For a general bioinformatic pipeline of how to asses these datasets, see Fig. 3. Though many of the enzymes used 


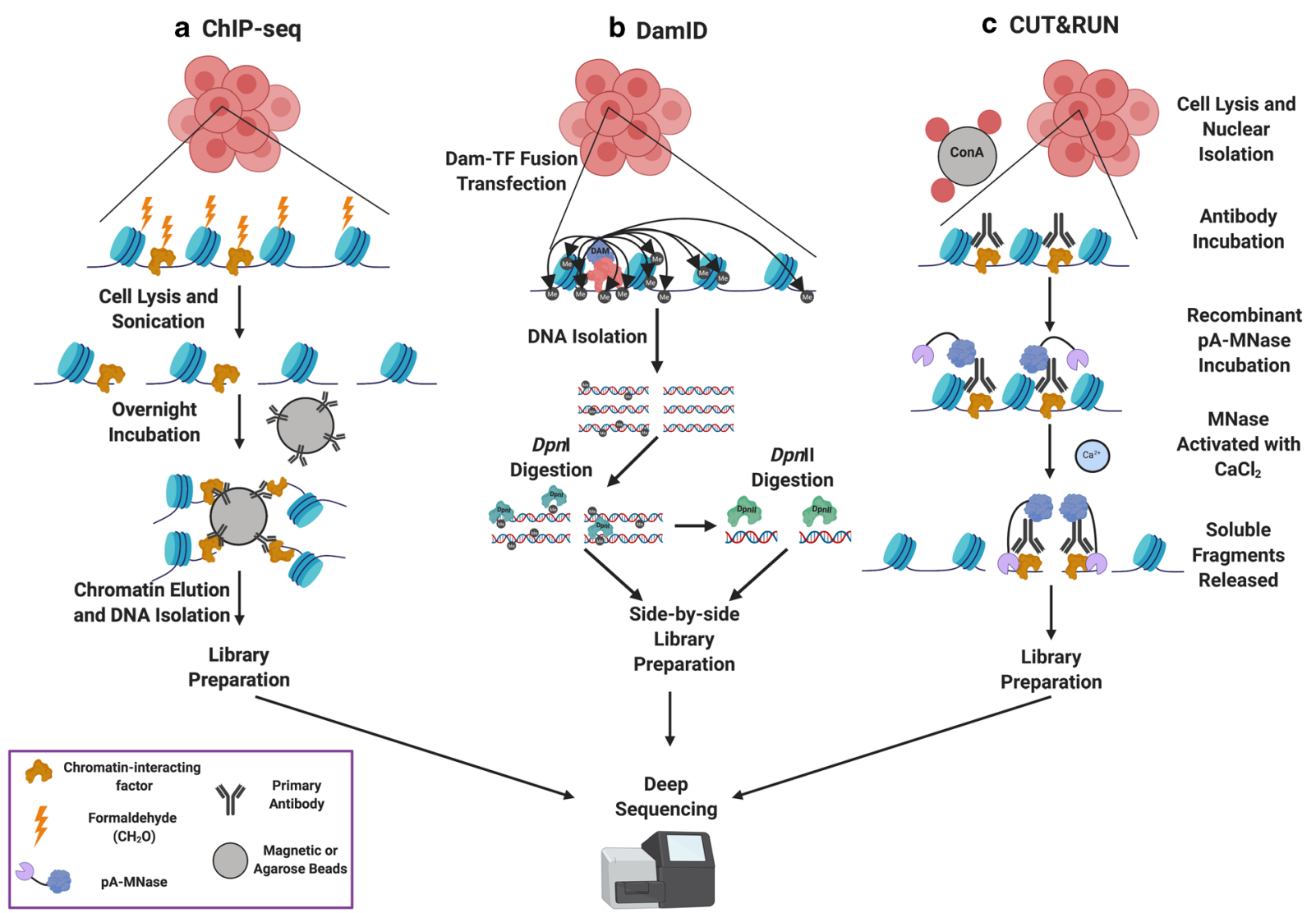

Fig. 2 Methods for profiling protein localization on chromatin. A DamID exploits the $E$. coli DNA adenine methyltransferase (Dam) by fusing it to a factor of interest and transfecting that plasmid into a cell. This construct methylates adenines located near factor binding sites. Genomic DNA can then be isolated and digested with $D p n \mathrm{I}$, which specifically cleaves at the sequence $\mathrm{G}^{\mathrm{m}}$ ATC. A portion of the digested DNA is then digested with DpnII, which cleaves unmethylated GATC to identify potential methylated sites out of Dam's range. Side-by-side libraries are built and subjected to deep sequencing. B ChIP-seq is an antibody-based technology that begins with crosslinking of factors to DNA, followed by chromatin shearing and antibody pulldowns for the factor of

to profile accessibility bear slight biases, the portraits of genome architecture that emerge are generally consistent when compared with each other.

\section{DNase-seq}

DNase-seq is a method used to examine chromatin accessibility with the non-specific DNA endonuclease DNase I, which preferentially degrades DNA unprotected by bound proteins (e.g., histone proteins; Fig. 1A). Prior to DNase-seq, DNase I had been used for footprinting, in which a gel would be run after DNase interest on either magnetic or agarose beads. Crosslinks are then reversed, and DNA is isolated for deep sequencing. C CUT\&RUN makes use of a recombinant Protein A-MNase (pA-MNase) fusion construct to bind to a primary antibody recognizing the factor of interest and specifically cleave DNA at factor binding sites, thereby creating small fragments that can be isolated from nuclei and used as a template for library construction and deep sequencing. CUT\&RUN offers near-base pair resolution and can be carried out under native (i.e., non-crosslinking) conditions due to its high sequencing signal-to-noise ratio. Figure created with Biorender. com

treatment both in the presence and absence of the protein of interest; blank regions on the gel would be inferred to be protected and/or inaccessible regions, whereas more nucleosome-depleted — or accessible—regions would be marked by greater cleavage site presence on a gel (Cappabianca et al. 1999; Dingwall et al. 1981; Galas and Schmitz 1978). Francis Collins' group first applied DNase I footprinting genome-wide in 2006, using microarray chips (DNase-chip) and massively parallel Sanger sequencing (Crawford et al. 2006a, b; Sabo et al. 2006). In 2008, Gregory Crawford's group further developed this technology through combination with 


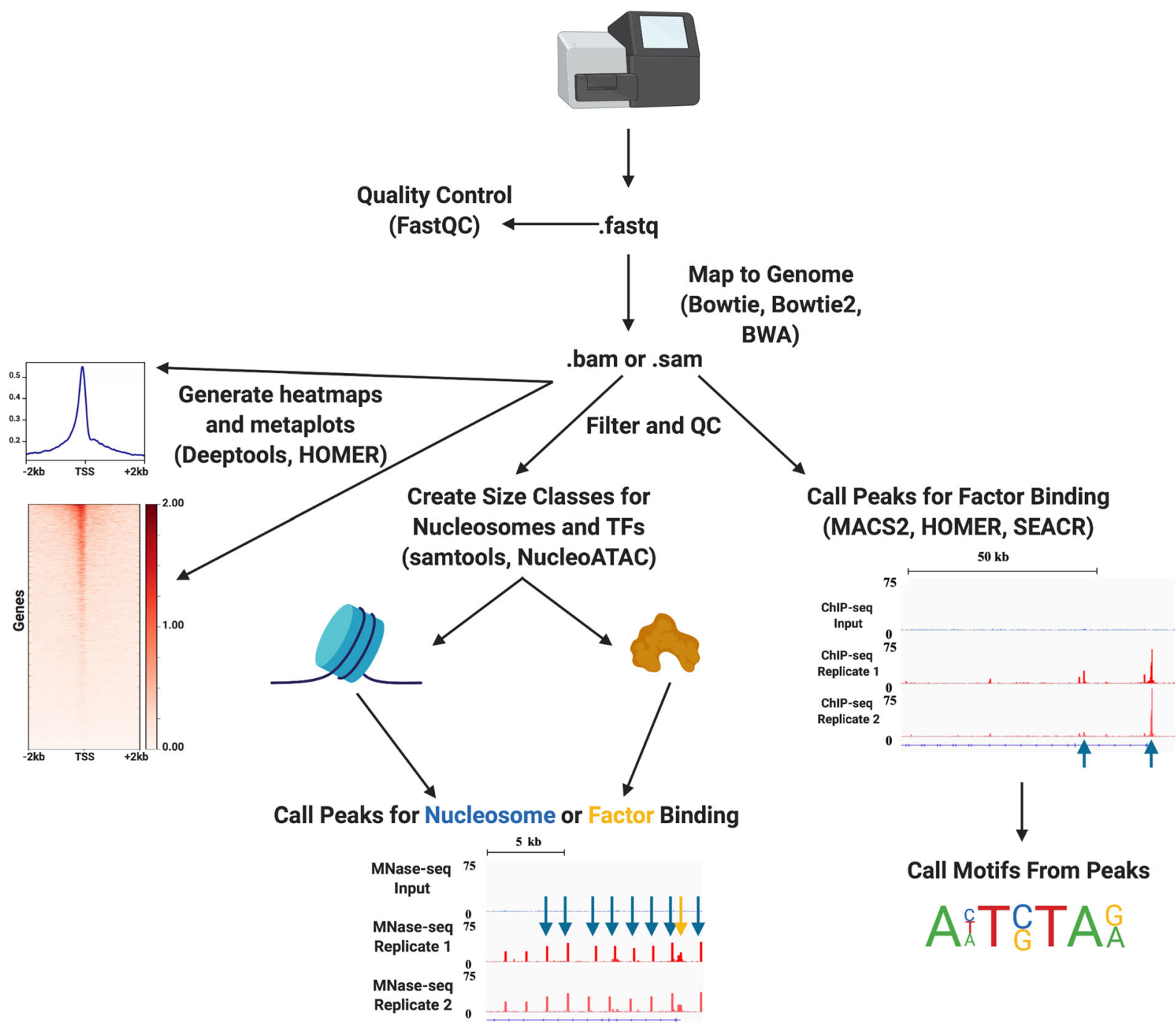

Fig. 3 A general bioinformatic pipeline for analyzing genomewide accessibility or profiling datasets. Although analyses vary depending on the technique used so as to minimize biases, we have presented a general pipeline for analyzing NGS-generated datasets. Following relevant quality control information (Andrews 2010), all sequencing experiments involve mapping to the genome of interest, generating files containing the sequence, alignment information, and quality information, known as .sam files (or, when compressed, .bam files; Langmead et al. 2009; Langmead and Saltzburg 2012; Li and Durbin 2009). These aligned files are filtered and used in downstream analyses; for studying

next-generation sequencing (Boyle et al. 2008) to greater success than the previous DNase-chip and DNase-seq experiments due to the increased resolution and quality offered over microarray technology. DNase-seq is applicable to all eukaryotic chromatin, including that of the common lab systems of plants, yeast, nematodes, flies, and mammalian cells. nucleosome and factor occupancy and positioning, size classes are created to divide inaccessible regions by the factors blocking their availability (Li, Handsaker et al. 2009; Schep et al. 2015). From the size-divided accessibility .bam files and the qualityfiltered localization .bam files, peaks can be called above local background scoring and/or compared with an input file (Heinz et al. 2010; Meers, Tenenbaum, and Henikoff, 2019; Zhang et al. 2008). From factor peaks, motifs can be called to determine which factors most likely bind these locations. Genomic data are typically viewed in the form of either heatmaps or metaplots (Heinz et al. 2010; Ramírez et al. 2016). Figure created with Biorender.com

DNase-seq is performed by isolating nuclei from cells, subjecting nuclei to general DNA digestion by DNase I, degrading RNA and proteins using RNases and Proteinase $\mathrm{K}$, respectively, purifying the DNA using a phenolchloroform extraction and ethanol precipitation, and gelextracting fragments of sizes corresponding to the desired class of factors (typically 50-100 bp for transcription 
factors and 130-160 bp for nucleosomes; (He et al. 2014). Purified and size-selected DNA is then used as a template for library construction. Those regions least frequently identified in sequencing of DNase-seq libraries have been most frequently degraded by DNase I and are inferred to be most accessible.

There is an intrinsic bias for DNase I to degrade DNA differently based on sequence, and this effect has been suggested to be related to the width of the minor groove (Lazarovici et al. 2013). This limitation must be considered when preparing a DNase-seq experiment (He et al. 2014). For factors that are difficult to profile by DNase-seq, a recent modification has incorporated the use of $0.1 \%$ formaldehyde crosslinking to assist in identification, termed XL-DNase-seq (Oh et al. 2019). Another DNaseseq modification, single-cell DNase-seq (scDNase-seq) has applied DNase-seq to individual cells and low-input primary tissue samples (Jin et al. 2015). While similar to traditional DNase-seq, scDNase-seq has been further optimized, applying the following alterations: inclusion of bacterial carrier DNA, lack of nuclear isolation, optimized DNase I digestion, lack of agarose gel separation, and altered PCR conditions. These optimizations are designed to minimize sample loss and facilitate amplification of small DNA fragments (Cooper et al. 2017).

DNase-seq has been highly influential in identifying putative regulatory regions of the genome. Regions that seldom appear in DNase-seq libraries, known as DNase I hypersensitive sites (DHSs), are often used as a proxy for active regulatory regions, such as enhancers and promoters. Attempts to identify these DHSs have resulted in highly influential papers covering almost all known cis-regulatory regions, including over 2.9 million DHSs (Thurman et al. 2012) and over 45 million transcription factor occupancy events (Neph et al. 2012). Additionally, DNase-seq has become a valuable tool for investigating epigenetic tissue- and cell typespecific differences, largely through the efforts of the ENCODE project and the Roadmap Epigenomic Consortium (Consortium 2012; Maurano et al. 2015; Roadmap Epigenomics et al. 2015).

\section{FAIRE-seq}

As an alternative to DNase-seq to identify accessible regions throughout the genome, formaldehyde-assisted isolation of regulatory elements (FAIRE) was developed in 2007. Rather than digesting unprotected DNA, FAIRE relies on crosslinking of histones to DNA, while unbound DNA is inferred to be accessible (Fig. 1B). FAIRE was first developed for use with DNA microarrays (Giresi et al. 2007) but was soon combined with next-generation sequencing technologies (Gaulton et al. 2010). Similar to DNase-seq, FAIRE-seq can be used to examine regulatory regions (including TSSs, promoters, and enhancers), also referred to as DHSs. FAIRE-seq has been validated in plant, yeast, nematode, fly, mouse, and human cells.

A typical FAIRE-seq experiment involves formaldehyde crosslinking, with the most abundant crosslinking targets being histone proteins (Rodríguez-Gil et al. 2018; Simon et al. 2012). Crosslinked chromatin is then sheared by sonication to approximately $200-300 \mathrm{bp}$ in size and DNA isolated via a phenol-chloroform extraction, wherein the highly crosslinked DNA remains in the organic phase and the non-crosslinked DNA is pulled to the aqueous phase. Non-crosslinked DNA from the aqueous phase can then be amplified and sequenced. Reads enriched in the sequencing pool tend to have lower nucleosome and factor binding and are therefore inferred to come from accessible regions.

A key disadvantage of FAIRE-seq experiments is that, while informative for histone-based chromatin architecture, regulatory regions that are bound by transcription factors or actively transcribed are also able to crosslink. The technique therefore relies on the presence of a mixed population for accurate accessibility profiling and is consequently lower resolution than the other techniques described in this review. As a result, fewer research groups have employed this technology; however, FAIRE-seq has been used to identify regulatory regions driving tumor development (Davie et al. 2015), to differentiate between ground-state and primedpluripotent cells (Murtha et al. 2015), and, similarly, to the ENCODE and Roadmap Epigenomic Consortium's DNase-seq efforts, to globally map accessible regulatory regions of chromatin (Bianco et al. 2015).

\section{MNase-seq}

MNase-seq is a method to assay nucleosome positioning and occupancy throughout the genome (Fig. 1C). Micrococcal nuclease (MNase) is an enzyme isolated from Staphylococcus aureus that displays both endo- and exonuclease activity to digest free DNA (Axel 1975; Dingwall et al. 1981). Similar to DNase I, MNase was used in DNA footprinting experiments to examine DNA accessibility before the invention of next-generation 
sequencing technologies (Cappabianca et al. 1999; Dingwall et al. 1981). MNase tiling arrays (MNasechip) were used by Ollie Rando, Corey Nislow, and Frank Pugh's groups, among others, to identify nucleosome positioning at high resolution before the advent of deep sequencing (Lee et al. 2007; Mavrich et al. 2008; Yuan et al. 2005). As with other techniques, MNase profiling was soon paired with next-generation sequencing technologies (Schones et al. 2008). MNase-seq has been used to map nucleosome architecture throughout eukaryotes from plants to yeast to humans.

An MNase-seq experiment begins with an in vivo formaldehyde crosslinking step that is designed to capture the interaction between proteins and DNA. This crosslinking allows bound proteins to shield their associated DNA from digestion by MNase. Following crosslinking, cells are lysed and digested with MNase, which is specifically activated by addition of $\mathrm{Ca}^{2+}$ to the lysis buffer. This digestion is halted by chelating the reaction, at which point the samples are RNase treated, crosslinks are reversed, and proteins are digested away from the chromatin. DNA is then isolated via a phenolchloroform extraction and examined on an agarose gel to ensure proper digestion of the DNA without degradation. As the most abundant DNA-contacting proteins are histones, this gel will typically display periodic laddering every 147 base pairs, representing mono-, di-, and trinucleosomes, and so on.

Traditional MNase-seq protocols advise excision of the mono-nucleosome band to enrich for these protected DNA fragments (Cui and Zhao 2012b; Rando 2010; Zhang and Pugh 2011); however, it is also possible to perform deep sequencing on the entirety of a MNase-digested sample (Henikoff et al. 2011). Fragments remaining after MNase cleavage were protected from digestion and are therefore inferred to have been protein-bound. Sequencing DNA protected by all crosslinked proteins can provide additional footprinting corresponding to both small proteins ( $<80 \mathrm{bp}$ shielded from digestion, e.g., transcription factors) as well as the traditional nucleosome arrays (Hainer and Fazzio 2015; Henikoff et al. 2011).

Importantly, MNase displays different digestion kinetics based on the amount of enzyme used to digest a population of cells (Mieczkowski et al. 2016); in addition, in the case of some genomic loci (such as fragile nucleosomes), high and low digestion profiles can provide drastically different information (Chereji et al. 2017; Mieczkowski et al. 2016; Weiner et al. 2010). It is therefore crucial to perform MNase-seq experiments on a uniform population with no-MNase, low-MNase, and high-MNase replicates. While MNase-seq has traditionally been limited by cellular input available, single-cell MNase-seq has recently been published (Lai et al. 2018).

MNase has a well-documented preference for cleavage of AT-rich naked DNA (Chung et al. 2010); however, this sequence preference is minute compared with preference due to chromatin accessibility (Allan et al. 2012). Nonetheless, techniques are available that can minimize bias due to MNase preference. Jay Shendure's lab has published an alternative, single-stranded library building protocol for MNase-seq, known as MNase-SSP that displays low sequence bias and enriches for shorter fragments than traditional MNase-seq, making for robust profiling of transcription factors (Ramani et al. 2019). In addition, a few closely related alternatives have been developed that utilize chemical cleavage of DNA, rather than enzymatic digestion. MPE-seq, developed by Bing Ren's group, uses methidiumpropyl-EDTA-Fe(II) (MPE) to preferentially cleave linker DNA between histones (Ishii et al. 2015). Steve Henikoff's group has also developed a chemical DNA cleavage technique, using a mutation in H4 (S47C) to create a site-specific nuclease by phenanthrolinemediated chelation of copper, which locally cleaves DNA at the dyad axis in the presence of peroxide (Chereji et al. 2018).

MNase-seq has been used to profile nucleosome occupancy and positioning changes at regulatory regions as a result of cellular differentiation, highlighting key changes in embryonic stem cell enhancers (West et al. 2014). Furthermore, MNase-seq can even be used to profile paused Pol II positioning, a trend that has been confirmed by parallel Pol II ChIP-seq (Teves and Henikoff 2011). Interestingly, MNase-seq profiling can be used to reliably predict $3 \mathrm{D}$ genome interactions and higher-order chromatin structures (Schwartz et al. 2019; Zhang et al. 2017). Because of its ability to capture transitory interactions via crosslinking, MNase-seq is one of the most versatile chromatin accessibility profiling techniques.

\section{ATAC-seq}

The assay for transposase accessibility and deep sequencing (ATAC-seq) is an additional technology to assess accessible chromatin. ATAC-seq involves the use of a hyperactive Tn5 transposase to insert sequencing adapters into open regions of chromatin to then sequence those regions through next generation 
sequencing (Buenrostro et al. 2013) Fig. 1D). Unlike other accessibility-profiling techniques, ATAC-seq was only recently developed (Buenrostro et al. 2013), though it has been adapted for use at a single locus (ATAC-qPCR; (Yost et al. 2018). Although ATAC-seq is a relatively new technique, the enzyme used, Tn5 transposase, was one of the first transposases identified, and has been used for in vitro transposition experiments for over 20 years (Goryshin and Reznikoff 1998; Naumann and Reznikoff 2002; Reznikoff 2003; Reznikoff 2008). Tn5 operates by a DNA-mediated "cut-and-paste" mechanism, wherein the transposase excises a segment of DNA, binds to a target DNA site, induces a double-strand break, and inserts the transposon into the new locus (Ivics et al. 2009). In ATAC-seq, Tn5 is loaded with a transposon designed to add sequencing adapters at the insertion point, forming a functional transposome. ATAC-seq has been used to map open chromatin in yeast, plants, nematodes, flies, mammals, and even frozen tissues (Corces et al. 2017).

ATAC-seq is performed in two to three basic steps consisting of cellular lysis and DNA transposition steps and DNA extraction and amplification (Buenrostro et al. 2013). Various ATAC-seq protocols have been developed including the original ATAC-seq (Buenrostro et al. 2013), FAST-ATAC-seq, which was designed for blood cells (Corces et al. 2016), and Omni-ATAC-seq (Corces et al. 2017), largely differing in the detergents used in cellular lysis. Because ATAC-seq relies on insertion to accessible DNA, rather than digestion of protected DNA, the technique is prone to sequencing contamination by mitochondrial DNA. Because of this prevalence, methods have been developed to reduce mitochondrial reads in ATAC-seq (Corces et al. 2017; Montefiori et al. 2017; Rickner et al. 2019).

ATAC-seq has successfully been used to assess chromatin accessibility in single cells (Buenrostro et al. 2015; Mulqueen et al. 2019) and from frozen tissue (Corces et al. 2017), and therefore the technique is be a valuable tool for confronting core genomic issues of cell heterogeneity and low sample availability. Indeed, Jay Shendure's group has published 85 different chromatin accessibility patterns (largely cell type-specific) based on single-cell indexed ATAC-seq in various mouse tissues (Cusanovich et al. 2018). In addition, Howard Chang's and William Greenleaf's groups have published accessibility studies in a litany of primary human cancers using ATAC-seq (Corces et al. 2018). ATAC has further been paired with visualization and flow cytometry (ATAC-see) to allow direct imaging, quantitation, and cell sorting as results of genome accessibility (Chen et al. 2016).

\section{Summary}

Techniques used to measure chromatin accessibility rely on two basic principles: first, that proteins can shield DNA from digestion and second, that histone proteins are the most prominent proteins interacting with DNA. DNase-seq, MNase-seq, and ATAC-seq fundamentally rely on the first principle, while FAIRE-seq and MNaseseq rely more on the second principle; however, both principles are important to the discrete patterns of accessibility uncovered by each technique. The aforementioned techniques provide distinct-yet consistentsnapshots of nucleosome positioning and chromatin accessibility, and each technique has particular advantages and disadvantages (Table 1). These technologies have illuminated and verified the accessible state of the genome by orthogonal approaches and led to identification of approximately 3 million putative regulatory regions of the human genome (Thurman et al. 2012).

In parallel to mapping generally accessible regions of the genome, investigating the factors that interact with chromatin and regulate these accessible regions through factor-specific protein localization profiling is equally important to understanding the basic principles of genome architecture.

Section 2: Methods in protein localization profiling on chromatin

Depending on their specific roles within the nucleus, chromatin-interacting proteins display characteristic patterns of genomic localization. By identifying the genomic regions at which proteins are found, it is possible to identify functional roles, motifs important for binding, and regulatory networks of DNA-templated processes in vivo. Like methods of measuring DNA accessibility, there are numerous approaches to identifying genomic binding sites of chromatin-interacting proteins that have gained popularity in recent years (Fig. 2), each of which has advantages and disadvantages (Table 1). Broadly, profiling methods must balance resolution of binding site identification with sample necessary to perform the experiment. Some methods, like ChIP-exo (Rhee and Pugh 2012), prioritize base-pair resolution, at the expense of increased necessary sample input; others, like DamID (van Steensel and Henikoff 2000), provide robust 


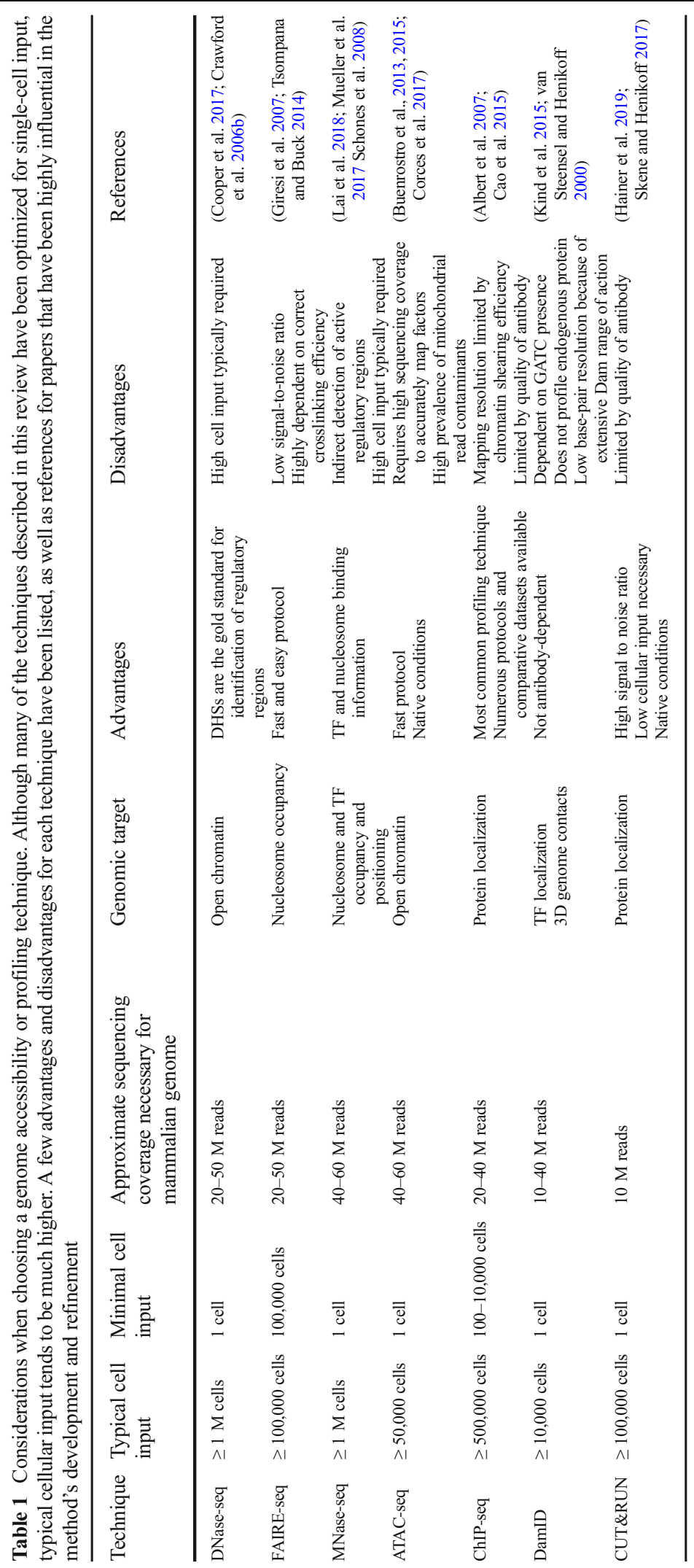


interaction data without the input limitations of higherresolution techniques. More recently, techniques derived from the chromatin immunocleavage (ChIC) method (Schmid et al. 2004) have emerged and are capable of providing high-resolution identification of binding sites with even ultra-low input samples. For a general bioinformatic pipeline on how to identify these genomic binding sites, see Fig. 3.

\section{ChIP-seq}

The most commonly used technique to assess the localization of chromatin-binding proteins, chromatin immunoprecipitation (ChIP) (Fig. 2A), was developed for use at a single locus using radioactive DNA labeling by Gilmour and Lis (1984) and formaldehyde crosslinking and gelbased imaging by Solomon and Varshavsky (1985). This technique had been in use for many years before being adapted for deep sequencing after library construction to examine genomic identification of a chromatin-interacting protein's binding site (Albert et al. 2007). Based on the initial radiolabeling experiments, ChIP-chip, a technique in which ChIP DNA is hybridized to DNA microarrays against various genomic loci, was developed in 2000 as the first broad genomic application of ChIP (Ren et al. 2000). ChIP was combined with quantitative PCR (ChIPqPCR) as a way to examine protein occupancy at multiple locations in a quantitative manner that was more targeted than ChIP-chip, but less restrictive than single-locus radiolabeled ChIP (Irvine et al. 2002). ChIP-seq robustly profiles protein-DNA interactions throughout eukaryotic species.

A ChIP experiment typically begins with a formaldehyde incubation designed to crosslink the lysines of interacting proteins with local DNA. Cells are then lysed to release crosslinked chromatin and subjected to unbiased sonication to shear the chromatin into short segments (typically between 100 and 400 base pairs). The sheared chromatin is then incubated with an antibody targeting the protein of interest followed by addition of a secondary IgG recognizing antibody that is typically coupled to sepharose or magnetic beads. Upon recognition of the epitope, the interacting region of DNA is pulled down with the protein to which it is crosslinked, thereby specifically isolating regions of DNA at which the protein crosslinks (and to which the protein is necessarily in close proximityapproximately $2 \AA$; (Perez-Romero and Imperiale 2007). Crosslinks are then reversed, protein is digested, and the
DNA is isolated to be used as a template for locus-specific qPCR or to be run on a gel.

ChIP-seq has been combined with various techniques to provide heightened resolution, including lambda exonuclease digestion (ChIP-exo and ChIP-nexus; (He et al. 2015; Rhee and Pugh 2012), UV-crosslinking (UV-ChIP; (Gilmour et al. 1991), and MNase digestion (Native ChIP; (O'Neill 2003). ChIP-exo and ChIP-nexus are two techniques that utilize nuclease digestion to improve ChIP-seq resolution to a near-base-pair level. ChIP-exo uses lambda exonuclease to digest unbound dsDNA 5'-3' until reaching a protein-DNA crosslink through which the nuclease cannot proceed (Rhee and Pugh 2012). Similar to ChIP-exo, ChIP-nexus relies on digestion of crosslinked DNA using lambda exonuclease; however, ChIP-nexus also incorporates a modified library build protocol and a barcode-based monitor of overamplification (He et al. 2015). In addition, ChIP-nexus requires only one 3 ' sequencing adaptor, reducing input requirements relative to traditional ChIP-seq (He et al. 2015). UV-ChIP utilizes UV light as a zerolength in vivo crosslinking agent that tests direct protein interaction; however, UV crosslinking provides low yields, making it unsuitable for low-input samples or infrequent interactions (Toth and Biggin 2000). Native ChIP uses MNase digestion as a gentler alternative to sonication that allows for identification of protein binding on noncrosslinked chromatin, and at substantially higher resolution than traditional ChIP-seq because it is no longer limited by sonication efficiency (O’Neill 2003).

The most pressing limitation to ChIP-seq experimentation is input; to produce a high signal-to-noise ratio, ChIPseq typically requires millions of input cells, particularly to examine transcription factor binding. As histones are far more abundant than other DNA-binding proteins, optimizing ChIP-seq technologies for low input has been far more fruitful using histones than factors. For traditional, crosslinking-based ChIP-seq techniques, $\mu$ ChIP-seq has been sufficient to profile histone modifications in 400 cells (Dahl et al. 2016), although ChIP has been paired with microfluidics technology (Cao et al. 2015; Rotem et al. 2015) to reduce necessary input to 100 cells for profiling histone modifications. Native ChIP-seq techniques have been more successful in reducing cellular input due to gentler chromatin shearing. In 2006, Carrier ChIP was successfully used to profile histone modifications in 50 cells (albeit with millions of "carrier" cells to reduce sample loss; (O’Neill et al. 2006), while more recent attempts have reduced cellular input for histone modification profiling to 500 cells (MINT-ChIP and ULI-NChIP) and 200 
cells (STAR-ChIP; (Liu et al. 2016; van Galen et al. 2016; Zhang et al. 2016). While transcription factors' abundance and transitory binding make them harder to profile in lowinput samples, two ChIP-based techniques have been successfully lowered cell input: ChIPmentation and Carrierassisted ChIP-seq. The first, ChIPmentation, was developed by Christoph Bock's group and utilizes Tn5 transposase to ligate sequencing adapters directly onto chromatin on beads (Schmidl et al. 2015); ChIPmentation was used to profile transcription factors in 100,000 cells. In addition, Jason Carroll's group has used carrier-assisted ChIP-seq to profile transcription factor localization in as few as 10,000 cells (Zwart et al. 2013).

As one of the first and most prominent genomic techniques, ChIP and its derivatives have been extraordinarily impactful in understanding regulation of chromatin interactions and transcription. To date, the term "chromatin immunoprecipitation" has almost 23,000 PubMed hits and over 9000 publicly available datasets in the ENCODE database, with far more stored in the NCBI Sequence Read Archive (Consortium 2012). Although ChIP-seq remains the gold standard of factor localization profiling, other techniques have been developed over the past 30 years to examine factor localization through different approaches.

\section{DamID}

DamID presents a non-ChIP alternative to locating proteins on chromatin (Fig. 2B) (van Steensel and Henikoff 2000). DamID makes use of a recombinant protein (Escherichia coli DNA Adenine Methyltransferase or Dam) fused to the chromatin-interacting protein of interest to identify genomic regions at which the protein interacts. Dam methylates adenine within the sequence GATC (Barras and Marinus 1989; Boivin and Dura 1998; Wines et al. 1996). As adenine methylation does not occur in most eukaryotes, DamID provides a native and specific readout for factor localization (Barras and Marinus 1989). Dam methylation can spread up to $5 \mathrm{~kb}$ from the protein-binding site (van Steensel and Henikoff 2000), highlighting the tradeoff between resolution and specificity balanced in DamID experiments. Additionally, more accessible regions of the genome are more likely to be methylated by Dam (Greil et al. 2006), a variable that is controlled for by profiling with transfection of unfused Dam. Although DamID was pioneered with Southern blotting and quantitative PCR (qPCR) as methylation quantitation, they have since been supplanted by next-generation sequencing technologies (Aughey et al. 2019; Greil et al. 2006). DamID is most commonly applied in Drosophila cells but has been used in yeast, C. elegans, Arabidopsis, mice, and human cells, illustrating a more versatile range of profiling.

A typical DamID experiment involves construction of a plasmid with Dam fused to the $\mathrm{N}$ - or C-terminus of the protein of interest. The plasmid is then transfected into the cells to be examined, as are a control plasmid containing Dam alone and an empty vector. Genomic DNA is then isolated from the transfected cells and digested with the $D p n \mathrm{I}$ restriction enzyme. As $D p n \mathrm{I}$ exclusively and specifically digests $\mathrm{G}^{\mathrm{m}}$ ATC, fragments generated from this digestion are inferred to have been in close proximity to the chromatin-interacting protein of interest. Adapters are ligated to the DpnI-digested fragments, and the DNA is then treated with $D p n I I$, a restriction enzyme that cleaves only unmethylated GATC, to doubly select for $\mathrm{G}^{\mathrm{m}}$ ATC in the genome. DNA libraries are then amplified and can be submitted for deep sequencing.

DamID has not reached the same popularity as ChIPseq but presents some notable strengths. First, DamID is not dependent on antibodies to profile factor binding, a significant advantage for profiling understudied proteins. Additionally, DamID was the first method by which one could confirm ChIP data by an alternate approach. DamID is, however, disadvantaged by the fact that the profiled protein is not endogenous to the host cells. The binding sites of a Dam fusion construct will often be comparable with an endogenous protein, but likely not identical due to the presence of the Dam construct itself as well as its plasmid-based expression. Additionally, DamID requires a genetically tractable system that can be transfected with the Dam fusion plasmid. Furthermore, DamID is limited by its low resolution; because Dam can methylate residues up to $5 \mathrm{~kb}$ from the fusion protein's binding site, and extensive false positives can be found (van Steensel and Henikoff 2000). Because of this range of methylation, DamID is unlikely to reach the resolution offered by ChIP-based techniques; DamID is not, however, constrained by the same input limitations, and has been used to profile transcription factor binding from 1000 ES cells (Tosti et al. 2018) and even single cells (Lai et al. 2019). Although ChIP-seq (and more recently, CUT\&RUN) has largely superseded DamID for factor localization, DamID is becoming more popular in studying broader chromatin features; for instance, Chromatin Accessibility Targeted DamID (CATaDA) has been 
developed to assess open chromatin (Aughey et al. 2018). CATaDa utilizes an untethered Dam protein to methylate regions of open chromatin, leaving nucleosome-bound DNA unmethylated (Aughey et al. 2018). Split DamID has also been used to profile cooccupancy of two proteins at genomic loci, acting in a similar manner to a yeast two-hybrid screen (Hass et al. 2015), and a catalytically inactive DpnI-GFP fusion construct has been used to examine Dam-driven GATC methylation in real-time using microscopy (Kind et al. 2015).

\section{CUT\&RUN}

Cleavage under targets and release using nuclease (CUT\&RUN) was developed by Skene and Henikoff in 2017 as a genome-wide modification of Ulrich Laemmli's group's 2004 ChIC technique, in which a recombinant Protein A fused to micrococcal nuclease (pA-MNase) can be combined with a primary antibody to specifically target MNase and cleave DNA surrounding sites where the protein of interest binds (Fig. 2C; (Schmid et al. 2004). Similar techniques include chromatin endogenous cleavage (ChEC; (Schmid et al. 2004), in which involves a Cterminal fusion of MNase to a protein of interest and ChEC-seq, a genome-wide pairing of ChEC and nextgeneration sequencing (Zentner et al. 2015). While ChEC has been successfully applied to assess the localization of multiple proteins (Baptista et al. 2017; Grunberg et al. 2016; Grunberg and Zentner 2017; Warfield et al. 2017; Zentner et al. 2015), the technique is limited by a need to specifically tag the protein of interest. CUT\&RUN, on the other hand, utilizes a recombinant $\mathrm{pA}-\mathrm{MNase}$ protein to recognize any primary antibody with compatible $\mathrm{IgG}$ backbones. Although CUT\&RUN is a recently developed technique, it has been used to profile protein-DNA interactions in Arabidopsis, yeast, flies, mice, and human cells, demonstrating a versatile range of application.

A CUT\&RUN experiment involves either a nuclear isolation with a hypotonic buffer to lyse the cells (Hainer and Fazzio 2019; Skene and Henikoff 2017) or cell permeabilization with digitonin (Skene et al. 2018) and lectincoated concanavalin A magnetic beads to isolate the nuclei. Subsequent steps are carried out in the bead-bound nuclei until the protected DNA fragments are released prior to library preparation. Primary antibody targeting the protein of interest is added and allowed to freely diffuse into the nuclei, followed by addition of recombinant pAMNase, which recognizes the IgG backbone of the primary antibody and is therefore specifically directed to the protein of interest's binding sites on chromatin. The MNase is then activated by addition of $\mathrm{Ca}^{2+}$ and digested in an ice-water bath (for sub-optimal MNase digestion kinetics) to cleave DNA and release the protein-bound fragments into the supernatant. Released fragments are then RNase treated, digested with Proteinase K, purified, and used as input for library construction. CUT\&RUN experiments are performed in tandem with a replicate in which the primary antibody is either left out of the sample or replaced with an IgG control, measuring background cutting by the free pA-MNase construct and correcting for an inherent bias towards more accessible regions of the genome. In addition, heterologous DNA can be spiked-in to the reaction upon chelating the MNase digestion (Skene and Henikoff 2017) or contaminating E. coli DNA from the pA-MNase purification can be used as a spike in (Meers et al. 2019). CUT\&RUN provides a high signalto-noise ratio, with the reduced background allowing thorough sequencing with approximately 10 million reads, whereas a ChIP-seq experiment requires 20-40 million reads to accurately assess protein binding.

CUT\&RUN has proven to be adaptable to numerous alterations to suit experimental contexts, most of which have been developed by Steve Henikoff's group. One such adaptation is robotic automation of the protocol for highthroughput profiling (AutoCUT\&RUN; (Janssens et al. 2018). In addition, Henikoff's group has published CUT\&RUN.Salt, a method that allows chromatin fractionation based on solubility and is especially useful for profiling centromeric or otherwise insoluble chromatin under typical conditions (Thakur and Henikoff 2018). To improve efficiency of pA-MNase-antibody binding, Henikoff's group has engineered a recombinant Protein A-Protein G-MNase fusion construct that allows for profiling of non-rabbit antibodies without a secondary antibody step (Meers et al. 2019). Finally, CUT\&RUN has been combined with traditional ChIP (CUT\&RUN.ChIP) that allows one to ChIP for protein complexes present within released CUT\&RUN fragments (Brahma and Henikoff 2019). The general CUT\&RUN technique therefore appears flexible to profile protein localization for a variety of experimental designs and desired outcomes.

In 2019, the first single-cell genome-wide profiling of chromatin-bound proteins using CUT\&RUN was published to examine pluripotency factors in murine embryonic stem cells (Hainer et al. 2019). In addition to profiling in single cells, factor binding was profiled in individual early blastocysts (consisting of between 30- 
50 cells each), an application not previously possible using ChIP-based techniques. More recently, Cleavage Under Targets and Tagmentation, or CUT\&Tag, was developed as a modification on CUT\&RUN that uses a recombinant Protein A-Tn5 transposase fusion instead of a recombinant $\mathrm{pA}-\mathrm{MNase}$ fusion protein (Kaya-Okur et al. 2019). CUT\&Tag has been used to profile histone modifications in single cells, although it has not yet been used to profile transcription factor binding in single cells (Kaya-Okur et al. 2019). In addition to CUT\&Tag, a similar single-cell modification of ChIC, scChIC-seq, which involves tethering of MNase to a specific antibody and cleavage of target sites using the antibody to direct the MNase, then selectively amplifying cleaved fragments by PCR was developed (Ku et al. 2019). Between CUT\&RUN, uliCUT\&RUN, CUT\&Tag, ChEC-seq, and ChIC-seq, ChIC- and ChEC-derived techniques appear poised to facilitate the next era of chromatin-interacting factor profiling.

\section{Summary}

As genomic technique refinement has allowed researchers to identify factor binding sites on chromatin and DNA accessibility with high resolution, the limitations of standard techniques have become more and more apparent. Because of differences due to cellular heterogeneity, inconsistent enzyme digestion kinetics, and untargeted sample isolation, recent advances in genomic techniques have focused on reducing necessary sample input and background signal. These technical improvements have made it possible to examine genome architecture and factor-binding profiles in individual cells, low-input samples like patient biopsies, and subsets of heterogeneous cellular populations. What has emerged from genomic studies of accessibility and factor binding is a complex picture of DNA templated activities regulated by chromatin architecture.

Profiling of genome accessibility and factor binding has set the stage for identification of genomic regulatory mechanisms; however, these techniques are merely a start towards understanding the gene regulation on a mechanistic level. These data must be integrated to understand how transcriptional and cellular networks function cooperatively and antagonistically to shape the functional genome. Additionally, comparisons between cell types will be important to provide insight into the ways in which a common suite of factors drive cell type-specific functions.
Acknowledgments We thank members of the Hainer lab for critical reading of this article.

Author contributions DCK and SJH wrote the manuscript.

Funding information This work was supported by a Charles E. Kaufman Foundation New Investigator Award and National Institutes of Health grant 1R35GM133732-01 to SJH.

Open Access This article is distributed under the terms of the Creative Commons Attribution 4.0 International License (http:// creativecommons.org/licenses/by/4.0/), which permits unrestricted use, distribution, and reproduction in any medium, provided you give appropriate credit to the original author(s) and the source, provide a link to the Creative Commons license, and indicate if changes were made.

\section{References}

Albert I, Mavrich TN, Tomsho LP, Qi J, Zanton SJ, Schuster SC, Pugh BF (2007) Translational and rotational settings of H2A.Z nucleosomes across the Saccharomyces cerevisiae genome. Nature 446:572-576. https://doi.org/10.1038/nature05632

Allan J, Fraser RM, Owen-Hughes T, Keszenman-Pereyra D (2012) Micrococcal nuclease does not substantially bias nucleosome mapping. J Mol Biol 417:152-164. https://doi. org/10.1016/j.jmb.2012.01.043

Andrews S (2010) FastQC: a quality control tool for high throughput sequence data. Available online at: http://www. bioinformatics.babraham.ac.uk/projects/fastqc

Aughey GN, Cheetham SW, Southall TD (2019) DamID as a versatile tool for understanding gene regulation. Development (Cambridge, England) 146:dev173666. https://doi.org/10.1242/dev.173666

Aughey GN, Estacio Gomez A, Thomson J, Yin H, Southall TD (2018) CATaDa reveals global remodelling of chromatin accessibility during stem cell differentiation in vivo. Elife 7. https://doi.org/10.7554/eLife.32341

Axel R (1975) Cleavage of DNA in nuclei and chromatin with staphylococcal nuclease. Biochemistry 14:2921-2925. https://doi.org/10.1021/bi00684a020

Baptista $T$ et al (2017) SAGA is a general cofactor for RNA polymerase II transcription. Mol Cell 68:130-143 e135. https://doi.org/10.1016/j.molcel.2017.08.016

Barras F, Marinus MG (1989) The great GATC: DNA methylation in E. coli. Trends Genet 5:139-143. https://doi.org/10.1016 /0168-9525(89)90054-1

Beato M, Eisfeld K (1997) Transcription factor access to chromatin. Nucleic Acids Res 25:3559-3563. https://doi. org/10.1093/nar/25.18.3559

Bianco S, Rodrigue S, Murphy BD, Gevry N (2015) Global mapping of open chromatin regulatory elements by formaldehydeassisted isolation of regulatory elements followed by sequencing (FAIRE-seq). Methods Mol Biol 1334:261-272. https://doi. org/10.1007/978-1-4939-2877-4_17

Boivin A, Dura JM (1998) In vivo chromatin accessibility correlates with gene silencing in Drosophila. Genetics 150:1539-1549 
Boyle AP et al (2008) High-resolution mapping and characterization of open chromatin across the genome. Cell 132:311322. https://doi.org/10.1016/j.cell.2007.12.014

Brahma S, Henikoff S (2019) RSC-associated subnucleosomes define MNase-sensitive promoters in yeast. Mol Cell 73: 238-249 e233. https://doi.org/10.1016/j.molcel.2018.10.046

Buenrostro JD, Giresi PG, Zaba LC, Chang HY, Greenleaf WJ (2013) Transposition of native chromatin for fast and sensitive epigenomic profiling of open chromatin, DNA-binding proteins and nucleosome position. Nat Methods 10:12131218. https://doi.org/10.1038/nmeth.2688

Buenrostro JD et al (2015) Single-cell chromatin accessibility reveals principles of regulatory variation. Nature 523:486490. https://doi.org/10.1038/nature14590

Cao Z, Chen C, He B, Tan K, Lu C (2015) A microfluidic device for epigenomic profiling using 100 cells. Nat Methods 12: 959. https://doi.org/10.1038/nmeth.3488, https://www. nature.com/articles/nmeth.3488\#supplementaryinformation. Accessed 27 July 2015

Cappabianca L, Thomassin H, Pictet R, Grange T (1999) Genomic footprinting using nucleases. Methods Mol Biol 119:427442. https://doi.org/10.1385/1-59259-681-9:427

Chen X, Shen Y, Draper W, Buenrostro JD, Litzenburger U, Cho SW, Satpathy AT, Carter AC, Ghosh RP, East-Seletsky A, Doudna JA, Greenleaf WJ, Liphardt JT, Chang HY (2016) ATAC-see reveals the accessible genome by transposasemediated imaging and sequencing. Nat Methods 13:10131020. https://doi.org/10.1038/nmeth.4031 https://www. nature.com/articles/nmeth. 4031 \#supplementaryinformation. Accessed 17 Oct 2016

Chereji RV, Ocampo J, Clark DJ (2017) MNase-sensitive complexes in yeast: nucleosomes and non-histone barriers. Mol Cell 65:565-577 e563. https://doi.org/10.1016/j. molcel.2016.12.009

Chereji RV, Ramachandran S, Bryson TD, Henikoff S (2018) Precise genome-wide mapping of single nucleosomes and linkers in vivo. Genome Biol 19:19. https://doi.org/10.1186/s13059018-1398-0

Chung HR et al (2010) The effect of micrococcal nuclease digestion on nucleosome positioning data. PLoS One 5:e15754. https://doi.org/10.1371/journal.pone.0015754

Consortium EP (2012) An integrated encyclopedia of DNA elements in the human genome. Nature 489:57-74. https://doi. org/10.1038/nature11247

Cooper J, Ding Y, Song J, Zhao K (2017) Genome-wide mapping of DNase I hypersensitive sites in rare cell populations using single-cell DNase sequencing. Nat Protoc 12:2342-2354. https://doi.org/10.1038/nprot.2017.099, https://www.nature. com/articles/nprot.2017.099\#supplementary-information. Accessed 12 Oct 2017

Corces MR et al (2016) Lineage-specific and single-cell chromatin accessibility charts human hematopoiesis and leukemia evolution. Nat Genet 48:1193-1203. https://doi.org/10.1038/ng.3646

Corces MR et al (2018) The chromatin accessibility landscape of primary human cancers. Science 362:eaav1898. https://doi. org/10.1126/science.aav1898

Corces MR et al (2017) An improved ATAC-seq protocol reduces background and enables interrogation of frozen tissues. Nat Methods 14:959-962. https://doi.org/10.1038/nmeth.4396
Crawford GE et al (2006a) DNase-chip: a high-resolution method to identify DNase I hypersensitive sites using tiled microarrays. Nat Methods 3:503-509. https://doi.org/10.1038/nmeth888

Crawford GE et al (2006b) Genome-wide mapping of DNase hypersensitive sites using massively parallel signature sequencing (MPSS). Genome Res 16:123-131. https://doi. org/10.1101/gr.4074106

Cui K, Zhao K (2012a) Genome-wide approaches to determining nucleosome occupancy in metazoans using MNase-Seq. Methods Mol Biol 833:413-419. https://doi.org/10.1007 1978-1-61779-477-3_24

Cui K, Zhao K (2012b) Genome-wide approaches to determining nucleosome occupancy in metazoans using MNase-Seq. In: Morse RH (ed) Chromatin Remodeling: Methods and Protocols, vol 833. Humana Press, Totowa, pp 413-419. https://doi.org/10.1007/978-1-61779-477-3_24

Cusanovich DA et al (2018) A single-cell atlas of in vivo mammalian chromatin accessibility. Cell 174:1309-1324 e1318. https://doi.org/10.1016/j.cell.2018.06.052

Dahl JA et al (2016) Broad histone H3K4me3 domains in mouse oocytes modulate maternal-to-zygotic transition. Nature 537: 548-552. https://doi.org/10.1038/nature19360

Davie K, Jacobs J, Atkins M, Potier D, Christiaens V, Halder G, Aerts S (2015) Discovery of transcription factors and regulatory regions driving in vivo tumor development by ATACseq and FAIRE-seq open chromatin profiling. PLoS Genet 11:e1004994. https://doi.org/10.1371/journal.pgen.1004994

Dingwall C, Lomonossoff GP, Laskey RA (1981) High sequence specificity of micrococcal nuclease. Nucleic Acids Res 9: 2659-2673. https://doi.org/10.1093/nar/9.12.2659

Felsenfeld G (1992) Chromatin as an essential part of the transcriptional mechanim. Nature 355:219-224. https://doi. org/10.1038/355219a0

Furey TS (2012) ChIP-seq and beyond: new and improved methodologies to detect and characterize protein-DNA interactions. Nat Rev Genet 13:840-852. https://doi.org/10.1038/nrg3306

Galas DJ, Schmitz A (1978) DNAse footprinting: a simple method for the detection of protein-DNA binding specificity. Nucleic Acids Res 5:3157-3170. https://doi.org/10.1093/nar/5.9.3157

Gaulton KJ et al (2010) A map of open chromatin in human pancreatic islets. Nat Genet 42:255-259. https://doi. org/10.1038/ng.530

Gilmour D, Lis J (1984) Detecting protein-DNA interactions in vivo: distribution of RNA polymerase on specific bacterial genes. Proc Natl Acad Sci U S A 81:4

Gilmour D, Rougvie A, Lis J (1991) Protein-DNA cross-linking as a means to determine the distribution of proteins on DNA in vivo. Methods Cell Biol 35:369-381. https://doi.org/10.1016/S0091679X(08)60580-4

Giresi PG, Kim J, McDaniell RM, Iyer VR, Lieb JD (2007) FAIRE (formaldehyde-assisted isolation of regulatory elements) isolates active regulatory elements from human chromatin. Genome Res 17:877-885. https://doi. org/10.1101/gr.5533506

Goryshin IY, Reznikoff WS (1998) Tn5 in vitro transposition. J Biol Chem 273:7367-7374. https://doi.org/10.1074/jbc.273.13.7367

Greil F, Moorman C, van Steensel B (2006) DamID: Mapping of in vivo protein-genome interactions using tethered DNA adenine methyltransferase. Methods Enzymol 410:342-359. https://oi.org/10.1016/S0076-6879(06)10016-6 
Grunberg S, Henikoff S, Hahn S, Zentner GE (2016) Mediator binding to UASs is broadly uncoupled from transcription and cooperative with TFIID recruitment to promoters. EMBO J 35:2435-2446. https://doi.org/10.15252/embj.201695020

Grunberg S, Zentner GE (2017) Genome-wide mapping of protein-DNA interactions with ChEC-seq in Saccharomyces cerevisiae. J Vis Exp. https://doi.org/10.3791/55836

Hainer SJ, Boskovic A, McCannell KN, Rando OJ, Fazzio TG (2019) Profiling of pluripotency factors in single cells and early embryos. Cell 177:1319-1329 e1311. https://doi. org/10.1016/j.cell.2019.03.014

Hainer SJ, Fazzio TG (2015) Regulation of nucleosome architecture and factor binding revealed by nuclease footprinting of the ESC genome. Cell Rep 13:61-69. https://doi.org/10.1016/j. celrep.2015.08.071

Hainer SJ, Fazzio TG (2019) High-resolution chromatin profiling using CUT\&RUN. Curr Protoc Mol Biol 126:e85. https://doi.org/10.1002/cpmb.85

Hass MR et al (2015) SpDamID: Marking DNA bound by protein complexes identifies notch-dimer responsive enhancers. Mol Cell 59:685-697. https://doi.org/10.1016/j.molcel.2015.07.008

$\mathrm{He} \mathrm{HH}$ et al (2014) Refined DNase-seq protocol and data analysis reveals intrinsic bias in transcription factor footprint identification. Nat Methods 11:73. https://doi.org/10.1038 /nmeth.2762

He Q, Johnston J, Zeitlinger J (2015) ChIP-nexus enables improved detection of in vivo transcription factor binding footprints. Nat Biotechnol 33:395-401. https://doi.org/10.1038 /nbt.3121

Henikoff JG, Belsky JA, Krassovsky K, MacAlpine DM, Henikoff $\mathrm{S}$ (2011) Epigenome characterization at single base-pair resolution. Proc Natl Acad Sci U S A 108:18318-18323. https://doi.org/10.1073/pnas.1110731108

Irvine RA, Lin IG, Hsieh CL (2002) DNA methylation has a local effect on transcription and histone acetylation. Mol Cell Biol 22: 6689-6696. https://doi.org/10.1128/mcb.22.19.6689-6696.2002

Ishii H, Kadonaga JT, Ren B (2015) MPE-seq, a new method for the genome-wide analysis of chromatin structure. Proc Natl Acad Sci U S A 112:E3457-E3465. https://doi.org/10.1073 /pnas. 1424804112

Ivics Z, Li MA, Mátés L, Boeke JD, Nagy A, Bradley A, Izsvák Z (2009) Transposon-mediated genome manipulation in vertebrates. Nat Methods 6:415-422. https://doi.org/10.1038 /nmeth. 1332

Janssens DH, Wu SJ, Sarthy JF, Meers MP, Myers CH, Olson JM, Ahmad K, Henikoff S (2018) Automated in situ chromatin profiling efficiently resolves cell types and gene regulatory programs. Epigenetics Chromatin 11:74. https://doi. org/10.1186/s13072-018-0243-8

Jin W et al (2015) Genome-wide detection of DNase I hypersensitive sites in single cells and FFPE tissue samples. Nature 528:142-146. https://doi.org/10.1038/nature15740

Kaya-Okur HS et al (2019) CUT\&Tag for efficient epigenomic profiling of small samples and single cells. Nat Commun 10: 1930. https://doi.org/10.1038/s41467-019-09982-5

Kind J et al (2015) Single-cell dynamics of genome-nuclear lamina interactions. Cell 153:178-192. https://doi.org/10.1016/j. cell.2013.02.028

Kornberg R, Lorch Y (1999) Twenty-five years of the nucleosome, fundamental particle of the eukaryotic chromosome. Cell 98:285-294
$\mathrm{Ku}$ WL et al (2019) Single-cell chromatin immunocleavage sequencing (scChIC-seq) to profile histone modification. Nat Methods 16:323-325. https://doi.org/10.1038/s41592-019-0361-7

Lai A, Altemose N, White JA, Streets AM (2019) On-ratio PDMS bonding for multilayer microfluidic device fabrication. J Micromech Microeng 29. https://doi.org/10.1088/13616439/ab341e

Lai B et al (2018) Principles of nucleosome organization revealed by single-cell micrococcal nuclease sequencing. Nature 562 : 281-285. https://doi.org/10.1038/s41586-018-0567-3

Lammerding J (2011) Mechanics of the nucleus. Compr Physiol 1: 783-807. https://doi.org/10.1002/cphy.c100038

Lazarovici A et al (2013) Probing DNA shape and methylation state on a genomic scale with DNase I. Proc Natl Acad Sci U S A 110:6376-6381. https://doi.org/10.1073/pnas.1216822110

Lee W, Tillo D, Bray N, Morse RH, Davis RW, Hughes TR, Nislow C (2007) A high-resolution atlas of nucleosome occupancy in yeast. Nat Genet 39:1235-1244. https://doi.org/10.1038/ng2117, https://www.nature.com/articles/ng2117\#supplementaryinformation. Accessed 16 Sept 2017

Liu X et al (2016) Distinct features of H3K4me3 and H3K27me3 chromatin domains in pre-implantation embryos. Nature 537: 558-562. https://doi.org/10.1038/nature19362

Maurano MT, Haugen E, Sandstrom R, Vierstra J, Shafer A, Kaul R, Stamatoyannopoulos JA (2015) Large-scale identification of sequence variants influencing human transcription factor occupancy in vivo. Nat Genet 47:1393-1401. https://doi. org/10.1038/ng.3432

Mavrich TN et al (2008) Nucleosome organization in the Drosophila genome. Nature 453:358-362. https://doi. org/10.1038/nature06929

Meers MP, Bryson TD, Henikoff JG, Henikoff S (2019) Improved CUT\&RUN chromatin profiling tools. Elife 8. https://doi. org/10.7554/eLife.46314

Mieczkowski J, Cook A, Bowman SK, Mueller B, Alver BH, Kundu S, Deaton AM, Urban JA, Larschan E, Park PJ, Kingston RE, Tolstorukov MY (2016) MNase titration reveals differences between nucleosome occupancy and chromatin accessibility. Nat Commun 7:11485. https://doi.org/10.1038/ncomms11485, https://www.nature.com/articles/ncomms11485\#supplementaryinformation. Accessed 6 May 2016

Montefiori L et al (2017) Reducing mitochondrial reads in ATACseq using CRISPR/Cas9. Sci Rep 7:2451. https://doi. org/10.1038/s41598-017-02547-w

Mueller B, Mieczkowski J, Kundu S, Wang P, Sadreyev R, Tolstorukov MY, Kingston RE (2017) Widespread changes in nucleosome accessibility without changes in nucleosome occupancy during a rapid transcriptional induction. Genes Dev 31:451-462. https://doi.org/10.1101/gad.293118.116

Mulqueen RM et al. (2019) Improved single-cell ATAC-seq reveals chromatin dynamics of in vitro corticogenesis bioRxiv: 637256. https://doi.org/10.1101/637256

Murtha M et al (2015) Comparative FAIRE-seq analysis reveals distinguishing features of the chromatin structure of ground state- and primed-pluripotent cells. Stem Cells 33:378-391. https://doi.org/10.1002/stem.1871

Naumann TA, Reznikoff WS (2002) Tn5 transposase with an altered specificity for transposon ends. J Bacteriol 184:233240. https://doi.org/10.1128/jb.184.1.233-240.2002 
Neph S et al (2012) An expansive human regulatory lexicon encoded in transcription factor footprints. Nature 489:8390. https://doi.org/10.1038/nature11212

O'Neill L (2003) Immunoprecipitation of native chromatin: NChIP. Methods 31:76-82. https://doi.org/10.1016/s10462023(03)00090-2

O’Neill LP, VerMilyea MD, Turner BM (2006) Epigenetic characterization of the early embryo with a chromatin immunoprecipitation protocol applicable to small cell populations. Nat Genet 38:835-841. https://doi.org/10.1038/ng1820

Oh K-S, Ha J, Baek S, Sung M-H (2019) XL-DNase-seq: improved footprinting of dynamic transcription factors. Epigenetics Chromatin 12:30. https://doi.org/10.1186/s13072-019-0277-6

Perez-Romero P, Imperiale MJ (2007) Assaying protein-DNA interactions in vivo and in vitro using chromatin immunoprecipitation and electrophoretic mobility shift assays. Methods Mol Med 131:123-139

Ramani V, Qiu R, Shendure J (2019) High sensitivity profiling of chromatin structure by MNase-SSP. Cell Rep 26:24652476.e2464. https://doi.org/10.1016/j.celrep.2019.02.007

Rando OJ (2010) Genome-wide mapping of nucleosomes in yeast. Methods Enzymol 470:105-118. https://doi.org/10.1016 /S0076-6879(10)70005-7

Ren B et al (2000) Genome-wide location and function of DNA binding proteins. Science 290:2306-2309. https://doi. org/10.1126/science.290.5500.2306

Reznikoff WS (2003) Tn5 as a model for understanding DNA transposition. Mol Microbiol 47:1199-1206. https://doi. org/10.1046/j.1365-2958.2003.03382.x

Reznikoff WS (2008) Transposon Tn5. Annu Rev Genet 42:269-286. https://doi.org/10.1146/annurev.genet.42.110807.091656

Rhee HS, Pugh BF (2012) ChIP-exo method for identifying genomic location of DNA-binding proteins with near-singlenucleotide accuracy. Curr Protoc Mol Biol Chapter 21:Unit 21 24. https://doi.org/10.1002/0471142727.mb2124s100

Rickner HD, Niu S-Y, Cheng CS (2019) ATAC-seq assay with low mitochondrial DNA contamination from primary human CD4+ T lymphocytes. JoVE e59120. https://doi. org/10.3791/59120

Roadmap Epigenomics $C$ et al (2015) Integrative analysis of 111 reference human epigenomes. Nature 518:317. https://www. nature.com/articles/nature14248. Accessed 18 Feb 2015

Rodríguez-Gil A, Riedlinger T, Ritter O, Saul VV, Schmitz ML (2018) Formaldehyde-assisted Isolation of Regulatory Elements to measure chromatin accessibility in mammalian cells. JoVE e57272. https://doi.org/10.3791/57272

Rotem A, Ram O, Shoresh N, Sperling RA, Goren A, Weitz DA, Bernstein BE (2015) Single-cell ChIP-seq reveals cell subpopulations defined by chromatin state. Nat Biotechnol 33: 1165-1172. https://doi.org/10.1038/nbt.3383

Sabo PJ et al (2006) Genome-scale mapping of DNase I sensitivity in vivo using tiling DNA microarrays. Nat Methods 3:511518. https://doi.org/10.1038/Nmeth890

Schmid M, Durussel T, Laemmli UK (2004) ChIC and ChEC; genomic mapping of chromatin proteins. Mol Cell 16:147157. https://doi.org/10.1016/j.molcel.2004.09.007

Schmidl C, Rendeiro AF, Sheffield NC, Bock C (2015) ChIPmentation: fast, robust, low-input ChIP-seq for histones and transcription factors. Nat Methods 12:963. https://doi. org/10.1038/nmeth.3542 https://www.nature. com/articles/nmeth.3542\#supplementary-information. Accessed 17 Aug 2015

Schones DE et al (2008) Dynamic regulation of nucleosome positioning in the human genome. Cell 132:887-898. https://doi.org/10.1016/j.cell.2008.02.022

Schwartz U et al (2019) Characterizing the nuclease accessibility of DNA in human cells to map higher order structures of chromatin. Nucleic Acids Res 47:1239-1254. https://doi. org/10.1093/nar/gky1203

Simon JM, Giresi PG, Davis IJ, Lieb JD (2012) Using formaldehyde-assisted isolation of regulatory elements (FAIRE) to isolate active regulatory DNA. Nat Protoc 7: 256-267. https://doi.org/10.1038/nprot.2011.444

Skene PJ, Henikoff JG, Henikoff S (2018) Targeted in situ genomewide profiling with high efficiency for low cell numbers. Nat Protoc 13:1006. https://doi.org/10.1038/nprot.2018.015 https://www.nature.com/articles/nprot.2018.015 \#supplementary-information. Accessed 12 Apr 2018

Skene PJ, Henikoff S (2017) An efficient targeted nuclease strategy for high-resolution mapping of DNA binding sites. Elife 6. https://doi.org/10.7554/eLife.21856

Solomon MJ, Varshavsky A (1985) Formaldehyde-mediated DNA-protein crosslinking: a probe for in vivo chromatin structures. Proc Natl Acad Sci U S A 82:6470-6474. https://doi.org/10.1073/pnas.82.19.6470

Song L, Crawford GE (2010) DNase-seq: a high-resolution technique for mapping active gene regulatory elements across the genome from mammalian cells. Cold Spring Harb Protoc 2010:pdb prot5384. https://doi.org/10.1101/pdb.prot5384

Teves SS, Henikoff S (2011) Heat shock reduces stalled RNA polymerase II and nucleosome turnover genome-wide. Genes Dev 25:2387-2397. https://doi.org/10.1101/gad.178079.111 10.1101/gad.177675.111

Thakur J, Henikoff S (2018) Unexpected conformational variations of the human centromeric chromatin complex. Genes Dev 32:20-25. https://doi.org/10.1101/gad.307736.117

Thurman RE et al (2012) The accessible chromatin landscape of the human genome. Nature 489:75-82. https://doi. org/10.1038/nature11232

Tosti L et al (2018) Mapping transcription factor occupancy using minimal numbers of cells in vitro and in vivo. Genome Res 28:592-605. https://doi.org/10.1101/gr.227124.117

Toth J, Biggin MD (2000) The specificity of protein-DNA crosslinking by formaldehyde: in vitro and in drosophila embryos. Nucleic Acids Res 28:e4-e4. https://doi. org/10.1093/nar/28.2.e4

Tsompana M, Buck MJ (2014) Chromatin accessibility: a window into the genome. Epigenetics \& Chromatin 7:33. https://doi. org/10.1186/1756-8935-7-33

van Galen P et al (2016) A multiplexed system for quantitative comparisons of Chromatin Landscapes. Mol Cell 61:170 180. https://doi.org/10.1016/j.molcel.2015.11.003

van Steensel B, Henikoff S (2000) Identification of in vivo DNA targets of chromatin proteins using tethered Dam methyltransferase. Nat Biotechnol 18:424-428. https://doi. org/10.1038/74487

Wallrath LL, Lu Q, Granok H, Elgin SC (1994) Architectural variations of inducible eukaryotic promoters: preset and remodeling chromatin structures. Bioessays 16:165-170. https://doi.org/10.1002/bies.950160306 
Warfield L, Ramachandran S, Baptista T, Devys D, Tora L, Hahn S (2017) Transcription of nearly all yeast RNA polymerase IItranscribed genes is dependent on transcription factor TFIID. Mol Cell 68:118-129 e115. https://doi.org/10.1016/j. molcel.2017.08.014

Weiner A, Hughes A, Yassour M, Rando OJ, Friedman N (2010) High-resolution nucleosome mapping reveals transcriptiondependent promoter packaging. Genome Res 20:90-100. https://doi.org/10.1101/gr.098509.109

West JA, Cook A, Alver BH, Stadtfeld M, Deaton AM, Hochedlinger K, Park PJ, Tolstorukov MY, Kingston RE (2014) Nucleosomal occupancy changes locally over key regulatory regions during cell differentiation and reprogramming. Nat Commun 5:4719. https://doi. org/10.1038/ncomms5719

Wines DR, Talbert PB, Clark DV, Henikoff S (1996) Introduction of a DNA methyltransferase into Drosophila to probe chromatin structure in vivo. Chromosoma 104:332-340. https://doi.org/10.1007/Bf00337221

Yost KE, Carter AC, Xu J, Litzenburger U, Chang HY (2018) ATAC primer tool for targeted analysis of accessible chromatin. Nat Methods 15:304-305. https://doi.org/10.1038/nmeth.4663

Yuan GC, Liu YJ, Dion MF, Slack MD, Wu LF, Altschuler SJ, Rando OJ (2005) Genome-scale identification of nucleosome positions in S. cerevisiae. Science 309:626-630. https://doi. org/10.1126/science. 1112178
Zentner GE, Kasinathan S, Xin B, Rohs R, Henikoff S (2015) ChEC-seq kinetics discriminates transcription factor binding sites by DNA sequence and shape in vivo. Nat Commun 6: 8733. https://doi.org/10.1038/ncomms 9733

Zhang B et al (2016) Allelic reprogramming of the histone modification $\mathrm{H} 3 \mathrm{~K} 4 \mathrm{me} 3$ in early mammalian development. Nature 537:553-557. https://doi.org/10.1038/nature19361

Zhang H, Li F, Jia Y, Xu B, Zhang Y, Li X, Zhang Z (2017) Characteristic arrangement of nucleosomes is predictive of chromatin interactions at kilobase resolution. Nucleic Acids Res 45:12739-12751. https://doi.org/10.1093/nar/gkx885

Zhang Z, Pugh BF (2011) High-resolution genome-wide mapping of the primary structure of chromatin. Cell 144:175-186. https://doi.org/10.1016/j.cell.2011.01.003

Zwart W, Koornstra R, Wesseling J, Rutgers E, Linn S, Carroll JS (2013) A carrier-assisted ChIP-seq method for estrogen receptor-chromatin interactions from breast cancer core needle biopsy samples. BMC Genomics 14:232. https://oi. org/10.1186/1471-2164-14-232

Publisher's note Springer Nature remains neutral with regard to jurisdictional claims in published maps and institutional affiliations. 